\title{
Proliferative activity in endometrial stromal granulocytes throughout menstrual cycle and early pregnancy
}

\author{
D PACE, L MORRISON, J N BULMER \\ From the Department of Pathology, University of Leeds
}

SUMMARY The proliferative activity in endometrial stromal granulocytes was studied using two approaches. Firstly, mitotic activity was studied in paraffin wax embedded sections of normal nonpregnant endometrium and early pregnancy decidua stained with phloxine-tartrazine. Secondly, the monoclonal antibody $\mathrm{Ki} 67$ was applied to cryostat sections of similar tissues. Endometrial stromal granulocytes were identified by their labelling with NKH1, Dako T11, UCHL1 or Dako-LC. The percentage of cases in which endometrial stromal granulocytes showed mitosis was $25 \%, 75 \%, 86 \%$, and $93 \%$, respectively in proliferative, early secretory, mid secretory, and late secretory phases, and $14 \%$ in early decidua. There were at most one or two endometrial stromal granulocytes in mitosis per 10 high power fields. Double labelled cells were present in small numbers in proliferative endometrium and in moderate numbers in secretory endometrium. Only a few cells in early decidua double labelled with Ki67/T11; moderate numbers of cells double labelled with Ki67/Dako-LC.

It is concluded that proliferative activity does occur in endometrial stromal granulocytes and is particularly prominent in the late secretory phase.

Endometrial stromal granulocytes, also termed Körnchenzellen or $\mathrm{K}$ cells, are prominent in human endometrium in early pregnancy and in the secretory phase of the menstrual cycle. They are characterised by their phloxinophilic cytoplasmic granules and have a small, oval, or indented hyperchromatic nucleus. They have been thought to be derived from undifferentiated endometrial stromal cells under the influence of progesterone. ${ }^{1-3}$ Several recent reports of immunohistochemical studies indicate that endometrial stromal granulocytes are, in fact, lymphoid cells ${ }^{45}$ reactive for the leucocyte common antigen (CD45), and for the $\mathrm{T}$ cell antigens CD2 (E-rosette receptor), CD7, CD38 (OKT10), UCHL1 and MT1. Ritson and Bulmer also described unusually intense reactivity with NKH1, a marker of large granular lymphocytes and natural killer cells, ${ }^{6}$ although the cells were negative for the classic natural killer cell markers Leu 7 and Leu 11 (CD16). Thus endometrial stromal granulocytes seem to be CD2, CD7, CD38, NKH1 positive granulated lymphocytes which fail to react with classic mature $\mathrm{T}$ lymphocyte or natural killer cell markers. Their phenotype is similar to that of a small peripheral blood natural killer subset, ${ }^{7}$ but at present the kinetics and differentiation of endometrial stromal granulo-

Accepted for publication 4 August 1988 cytes are unknown. Marchand reported mitotic activity in granulated cells in human endometrium ${ }^{8}$ but his observation was not endorsed by other studies. ${ }^{29}$ Reports that endometrial stromal granulocytes are fully differentiated cells that are not seen in mitosis raises questions as to whether they influx into endometrium directly from the blood or, alternatively, differentiate in situ from bone marrow derived precursors.

In this study two approaches were used to investigate the proliferative activity of endometrial stromal granulocytes in human endometrium. Routinely processed and wax embedded sections of cyclical endometrium and early pregnancy decidua were stained with phloxine-tartrazine and the number, distribution, and mitotic activity of endometrial stromal granulocytes noted.

Secondly, fresh tissues from normal endometrium and early pregnancies were treated with monoclonal antibodies previously reported to react with endometrial stromal granulocytes. ${ }^{46} \mathrm{Ki67}$, which reacts with cells at all stages of the cell cycle other than $\mathrm{G}_{\mathrm{o}}$, was used as a marker of proliferation. ${ }^{10}$

\section{Material and methods}

Sections of normal endometrium from all stages of the 
menstrual cycle were extracted from the files of the University department of pathology, Leeds (proliferative phase $n=8$, secretory phase, early $n=$ 16 , mid $n=7$, late $n=15$ ). Seven cases of early pregnancy decidua were similarly selected. These sections were reviewed and if appropriate for menstrual dates, a further $4 \mu \mathrm{m}$ sections were stained with phloxine-tartrazine to show up the cytoplasmic granules.

Phloxine-tartrazine stained sections of the stratum functionalis of non-pregnant endometrium and the decidua of the pregnant cases were scanned. The number of endometrial stromal granulocytes occurring in 10 high power fields ( $\times 40$ lens, $\times 10$ eyepiece) was counted by one of the authors (DP) and the average was calculated for each case. The presence or absence of endometrial stromal granulocytes in mitoses was also noted (figs 1 and 2).

Fresh fragments of first trimester (eight to 10 weeks) decidualised endometrium $(n=6)$ were identified by their white-grey appearance and recovered from elective aspiration terminations of apparently healthy pregnancies. Fresh normal endometrium was obtained from curettage or hysterectomy specimens (proliferative phase $n=4$, secretory phase $n=13$ ). Five to $10 \mathrm{~mm}$ cube tissue fragments were snap frozen in liquid nitrogen cooled isopentane (BDH, Poole, Dorset) and stored in liquid nitrogen until sectioning. Cryostat sections were cut at 5-7 $\mu \mathrm{m}$, air dried overnight, and fixed for 10 minutes in acetone at room temperature. Sections were wrapped in aluminium foil and stored at $-20^{\circ} \mathrm{C}$ until use.

Five separate mouse monoclonal antibodies were used; dilutions, specificities, sources and references are detailed in table 1 .

\section{IMMUNOHISTOCHEMISTR Y}

Single immunoenzymatic labelling techniques

A standard indirect immunoperoxidase method was used to stain serial frozen sections of decidua and nonpregnant endometrium with monoclonal antibodies (table 1). Secondary antibody (peroxidase-conjugated rabbit anti-mouse immunoglobulin) was purchased from Dakopatts. In some cases the blue haematoxylin counterstain partially obscured the brown $3,3^{\prime}$ diaminobenzidine (DAB) nuclear reaction product obtained with Ki67. Hence selected sections were also labelled using a streptavidin-biotin-peroxidase kit (Zymed, California, USA). The sections were incubated sequentially with primary monoclonal antibodies (30 minutes), biotinylated antimouse immunoglobulin (10 minutes), and streptavidin-peroxidase (five minutes) according to manufacturer's instructions. The reaction was developed with the supplied aminoethylcarbazole (AEC) to give a bright red reaction product.

These single immunoenzymatic staining techniques were also used to compare the pattern observed using two monoclonal antibodies separately with that obtained when using both monoclonal antibodies simultaneously in a double immunoenzymatic labelling technique.

\section{Double immunoenzymatic labelling technique}

Double immunoenzymatic labelling was used to study the expression of the nuclear proliferation antigen Ki67 by cells expressing membrane antigens detected by NKH1, UCHL1, Dako LC and Dako T11. This was performed sequentially using an indirect immunoperoxidase or streptavidin-biotin-peroxidase method followed by the indirect alkaline phosphatase method. The peroxidase label was developed with DAB or AEC, as appropriate, to give a brown or red reaction product, and the alkaline phosphatase label was developed with fast blue 2B (Sigma Chemicals) to give a bright blue reaction product. The secondary antibody (alkaline phosphatase-conjugated rabbit anti-mouse immunoglobulin) was obtained from North East Biomed, Denham, England.

The method used has been described in detail previously." Tissues were initially treated with Ki67 using an indirect immunoperoxidase reaction or the streptavidin-biotin-peroxidase kit as described above. The immunoperoxidase technique was performed first as it has been reported that the DAB reaction product blocks antigenic sites on the first monoclonal antibody and therefore prevents the alkaline phosphatase-conjugated anti-mouse immunoglobulin reacting with the first monoclonal antibody, a potential source of cross reactivity. Standard controls were performed at all levels for both the immunoperoxidase and the alkaline phosphatase reactions. Serial sections on either side of the test section were labelled by an indirect immuno-

Table 1 Primary monoclonal antibodies

\begin{tabular}{|c|c|c|c|}
\hline Antibody & Specificity & Reference/source & Dilution \\
\hline $\begin{array}{l}\text { Dako-T11 } \\
\text { UCHL1 } \\
\text { Dako-LC } \\
\text { NKH1 }\end{array}$ & $\begin{array}{l}\text { E-rosette receptor (CD2) } \\
\text { T cells (70\% CD4 +, 35\% CD8 +) } \\
\text { Leucocyte common antigen (CD45) } \\
220000 \text { molecular weight protein } \\
\text { expressed by LGL's with natural } \\
\text { killer activity }\end{array}$ & $\begin{array}{l}\text { Dakopatts A/S, Denmark } \\
\text { Dakopatts A/Si } \\
\text { Dakopatts A/S } \\
\text { Coulter Clone, Luton, } \\
\text { Bedfordshire }\end{array}$ & $\begin{array}{l}1: 50 \mathrm{CS} \\
1: 10 \mathrm{CS} \\
1: 10 \mathrm{CS} \\
1: 100 \mathrm{PE}\end{array}$ \\
\hline Ki67 & Proliferating cells & Dakopatts $\mathbf{A} / \mathbf{S}^{9}$ & $1: 10 \mathrm{CS}$ \\
\hline
\end{tabular}

CS: Culture supernatant; PE: Peritoneal exudate; LGL: large granular lymphocyte. 


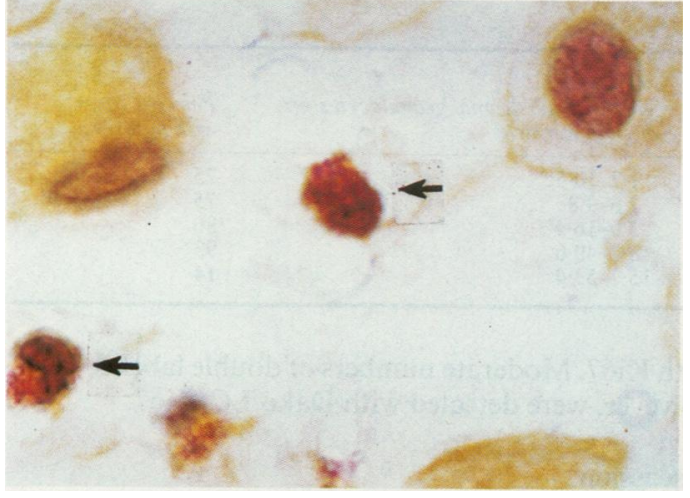

Fig 1 Endometrial stromal granulocytes (arrowed) in first trimester decidua. (Phloxine-tartrazine.)

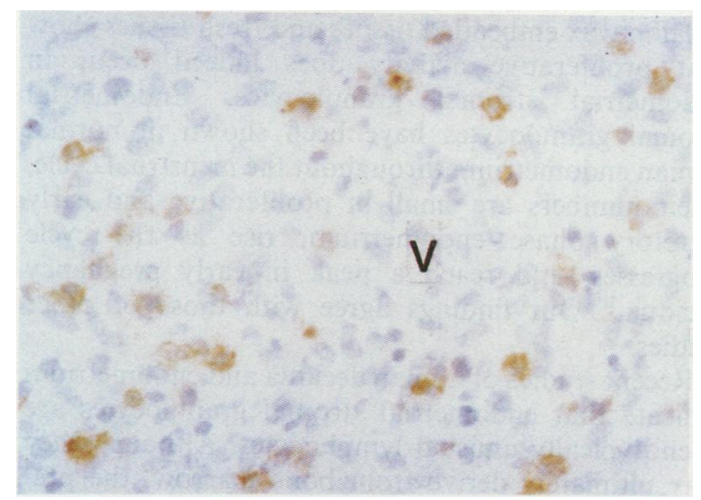

Fig $3 T 11$ positive cells around a spiral artery $(V)$. (Indirect immunoperoxidase (IIP) developed with DAB.)

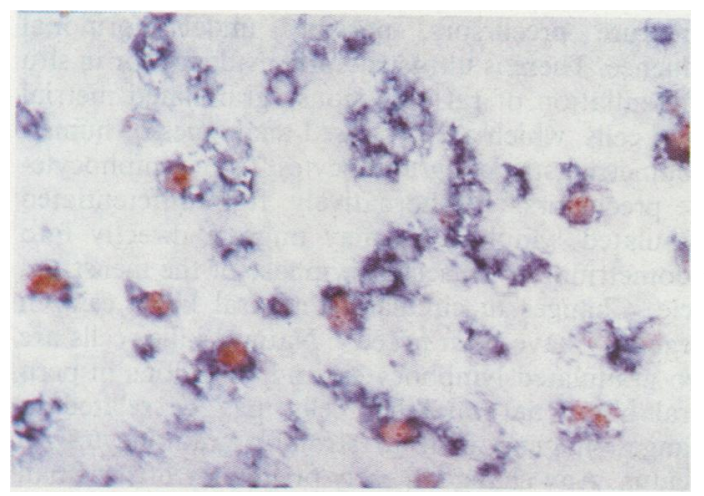

Fig 5 Double labelling; Ki67 (SAB, red), T11 (indirect alkaline phosphatase, IAP, blue).

Figs 2-6 Late secretory phase endometrium.

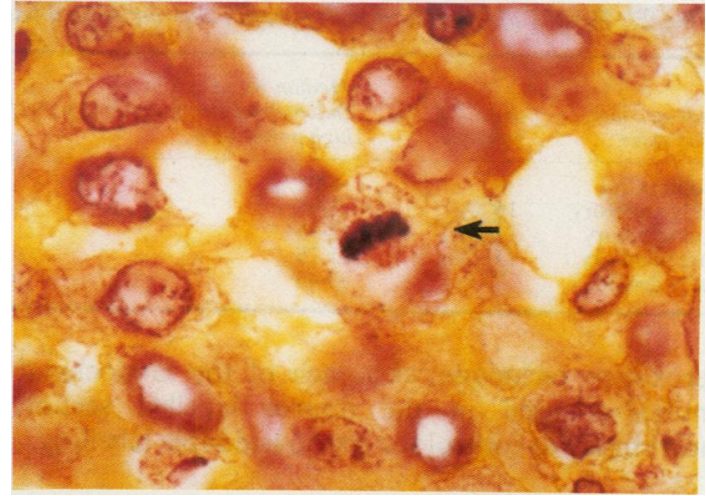

Fig 2 Endometrial stromal granulocytes in mitosis (arrowed). (Phloxine-tartrazine.)

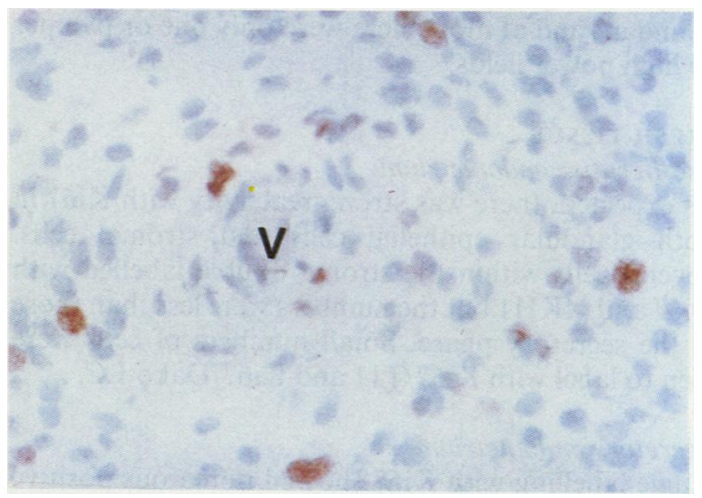

Fig 4 Ki67 positive cells around a spiral artery $(V)$. (Streptavidin-biotin kit (SAB))

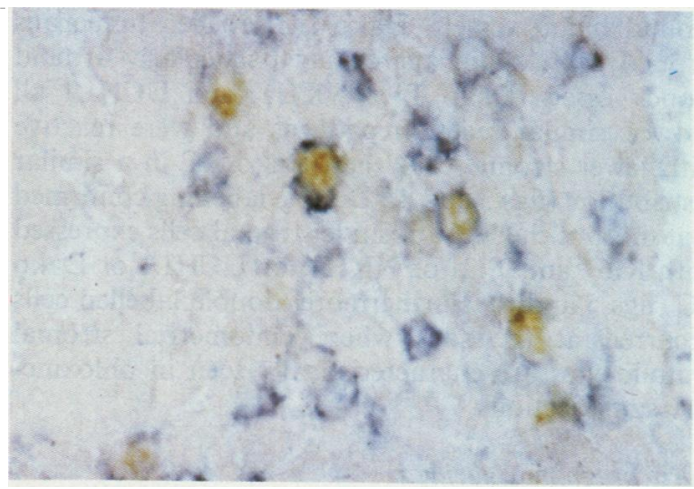

Fig 6 Double labelling; Ki67 (IIP, brown), NKHI (IAP, blue). 
Table 2 Results of formalin-fixed, paraffin wax embedded tissue

\begin{tabular}{lcclc}
\hline $\begin{array}{l}\text { Endometrium } \\
\text { cycle stage }\end{array}$ & $\begin{array}{l}\text { No } \\
\text { of cases }\end{array}$ & $\begin{array}{l}\text { Median No of } \\
\text { endometrial stromal granulocytes/ } \\
\text { high power field }\end{array}$ & $\begin{array}{l}\text { Range of } \\
\text { endometrial stromal granulocytes/ } \\
\text { high power field }\end{array}$ & $\begin{array}{l}\text { Per cent cases } \\
\text { with mitoses }\end{array}$ \\
\hline Proliferative & 8 & $8 \cdot 05$ & $1 \cdot 7-10 \cdot 5$ & 25 \\
Early secretory & 16 & 5.95 & $2 \cdot 6-9 \cdot 8$ & 75 \\
Mid secretory & 7 & $13 \cdot 15$ & $3 \cdot 0-16 \cdot 4$ & 86 \\
Late secretory & 15 & 21.75 & $8 \cdot 2-49 \cdot 6$ & 93 \\
Early decidua & 7 & 33.45 & $15 \cdot 7-53 \cdot 4$ & 14 \\
\hline
\end{tabular}

peroxidase technique with each of the monoclonal antibodies used in the double labelled section individually to control for spurious double labelling.

\section{Results}

The results for the paraffin wax embedded tissue samples are given in table 2. Mitotic figures were not abundant and at most there were only one or two per 10 high power fields.

\section{FRESH TISSUE}

\section{Proliferative endometrium}

As expected, there was. strong reactivity with $\mathrm{Ki} 67$ in both glandular epithelial cells and stromal cells. Several cells within the stroma double labelled with Ki67 and NKH1 but the numbers were less than those in the secretory phase. Small numbers of cells were seen to label with Ki67/T11 and Ki67/Dako LC.

\section{Secretory endometrium}

Single labelling with Ki67 showed numerous positive epithelial cells (particularly in early secretory phase samples). Numerous positive cells were also observed in the stroma between the glands, both as single cells and arranged in clusters, often aggregated particularly around blood vessels. Dako LC labelled numerous stromal cells, again aggregated particularly around blood vessels. Dako T11, NKH1, and UCHL1 all showed similar reaction patterns and were reactive with fewer stromal cells than Dako LC in a similar distribution (figs 3 and 4). Double labelling confirmed that most of the $\mathrm{Ki} 67$ positive stromal cells expressed both Ki67 and T11, or NKH1, or UCHL1 or Dako LC (figs 5 and 6). Furthermore, double labelled cells occurred at the sites where endometrial stromal granulocytes are characteristically seen in phloxinetartrazine sections.

\section{Early pregnancy decidua}

Ki67 positive cells were present in the stroma and varied from scanty to moderate in number but were less numerous than in the secretory endometrium. Double labelling was negative with NKH1, although there were numerous singly labelled NKH1 positive cells. Similarly, there were numerous T11 positive cells in decidua, but only the occasional cell double labelled with Ki67. Moderate numbers of double labelled cells, however, were detected with Dako LC/Ki67.

\section{Dișcussion}

Endometrial stromal granulocytes have previously been reported to be fully differentiated cells never seen in mitosis. ${ }^{29}$ The present results on both formalin-fixed paraffin wax embedded tissues and fresh tissues show that proliferative activity does indeed occur in endometrial stromal granulocytes. Endometrial stromal granulocytes have been shown in normal human endometrium throughout the menstrual cycle. Their numbers are small in proliferative and early secretory phase endometrium, rise as the cycle progresses, and reach a peak in early pregnancy decidua. ${ }^{10}$ Our findings agree with those of other studies.

Recent studies of human decidua and endometrium indicate that endometrial stromal granulocytes are phenotypically unusual lymphocytes. Although they may ultimately derive from bone marrow, the precursor cell is not known and the question is raised as to whether they influx into the endometrium directly from the blood as phenotypically unusual mature cells or differentiate in situ from bone marrow derived immature precursors, possibly under hormonal influence. There is ultrastructural evidence for in situ differentiation of rat and mouse granulated metrial gland cells, which are proposed analogues of human endometrial stromal granulocytes, from lymphocytelike precursors. ${ }^{1213}$ Alternatively, fully differentiated granulated lymphocytes may migrate directly into endometrium in the secretory phase of the menstrual cycle. Changes in circulating natural killer cells in pregnancy have been noted. ${ }^{14}$ Natural killer cells are also granulated lymphocytes, and variations in periheral blood natural killer cells may be related to changes in endometrial stromal granulocytes in decidua. Any change in early pregnancy of the small peripheral blood natural killer cell subset, which is phenotypically analogous to endometrial stromal granulocytes, ${ }^{7}$ remains to be investigated. Functional studies of endometrial stromal granulocytes separated and semi-purified from early pregnancy decidua show low but significant levels of cytotoxicity in a standard K562 chromium release assay for natural killer 
activity (Riston A, Bulmer JN, unpublished observations), and a phenotypically similar cell population has recently been described in the peripheral blood. ${ }^{7}$ The increased incidence of these cells, particularly in the late secretory/premenstrual endometrium and early decidua must indicate influx from the circulation, or multiplication in situ. The accumulation of CD2 positive, CD3 negative lymphocytes (endometrial stromal granulocytes) around arteries could result from their access to endometrium directly from the blood. Alternatively, a factor such as progesterone diffusing from the blood could influence division or differentiation of precursor lymphocytes in a perivascular location. This perivascular accumulation of endometrial stromal granulocytes was originally attributed to diffusion from the blood of circulating progesterone, causing morphological changes in stromal cells. ${ }^{23}$

Another possibility not previously considered is that endometrial stromal granulocytes are related to and could derive from intraepithelial lymphocytes as may occur in mucosal associated lymphoid tissue in the gastrointestinal tract. Endometrial stromal granulocytes certainly are present in an intraepithelial location between the gland epithelial cells in endometrium throughout the menstrual cycle and early pregnancy (Pace D, unpublished data). The importance of this finding is uncertain at present and is currently being investigated.

The proliferative activity of endometrial stromal granulocytes measured by the percentage of cases exhibiting mitoses and the number of cells double labelling with $\mathrm{Ki67}$ and the other monoclonal antibodies does not mirror the number of endometrial stromal granulocytes present. There seems to be a definite and pronounced increase in proliferative activity on progressing from the proliferative to the early secretory phase, although the numbers of endometrial stromal granulocytes remain roughly the same. This trend continues through the secretory phase with almost all cases $(93 \%)$ in the late secretory phase showing mitotic activity. Interestingly, in the early pregnancy decidua, although the numbers of endometrial stromal granulocytes increase, the proliferative activity apparently diminishes to even lower levels than that seen in proliferative endometrium.

In frozen sections of decidua most double labelled cells were Dako LC-positive but NKH1 and T11negative. These mitotically active cells may have represented macrophages which are known to be abundant in early pregnancy decidua. ${ }^{15}$ The phloxinetartrazine sections of early pregnancy decidua bear out the fact that very few endometrial stromal granulocytes are mitotically active.

Endometrial stromal granulocytes substantially diminish in number after the first trimester of pregnancy, and lack of proliferative activity in early pregnancy decidua may reflect the subsequent decrease in numbers. The predominance of endometrial stromal granulocytes in early pregnancy may also have a functional importance: maximum numbers of endometrial stromal granulocytes are observed around the time of blastocyst implantation $^{211}$ and a local immunoregulatory role has been proposed. Endometrial stromal granulocytes, however, are often not found locally at the tubal implantation site in ectopic tubal pregnancies, ${ }^{16}$ thus casting doubt on their role as an essential component in implantation.

We are grateful to the Yorkshire Regional Health Authority and Birthright for financial support.

\section{References}

1 Hamperl $H$. The granular endometrial stromal cells, a new cell type. J Pathol Bacteriol 1955;69:358-9.

2 Hamperl H, Hellweg G. Granular endometrial stromal cells. Obstet Gynaecol 1958;11:379-87.

3 Dallenbach-Hellweg $G$. The normal histology of the endometrium. In: Dallenbach-Hellweg G. Histopathology of endometrium. 3rd Edition. Berlin: Springer-Verlag, 1981:22-88.

4 Bulmer JN, Hollings D, Ritson A. Immunocytochemical evidence that endometrial stromal granulocytes are granulated lymphocytes. J Pathol 1987;153:281-8.

5 Bulmer JN, Sunderland CA. Bone marrow origin of endometrial granulocytes in the early human placental bed. $J$ Reprod Immunol 1983;5:383-7.

6 Ritson A, Bulmer JN. Endometrial granulocytes in human decidua react with a natural-killer (NK) cell marker, NKH1. Immunology 1987;62:329-31.

7 Lanier LL, Le AM, Civin CI, Loken MR, Phillips JH. The relationship of CD16 (leu-11) and leu 19 (NKH-1) antigen expression on human peripheral blood NK cells and cytotoxic lymphocytes. J Immunol 1986;136:4480-6.

8 Marchand F. Beitrag zur kenntnis der normalen und pathologischen. Histologie der Decidua. Archiv Gynäkologie 1904; 72:155.

9 Kazzaz BA. Specific endometrial granular cells. A semi-quantitative study. Eur J Obstet Gynaecol 1972;3:77-84.

10 Gerdes J, Lernke H, Baisch H, Wacker H, Schwab U, Stein H. Cell cycle analysis of a cell proliferation-associated human nuclear antigen defined by the monoclonal antibody $\mathrm{Ki}-67$. J Immunol 1984;133:1710-5.

11 Bulmer JN, Johnson PM. Immunohistological characterization of the decidual leucocytic infiltrate related to endometrial gland epithelium in early human pregnancy. Immunol 1985;55:35-44.

12 Peel S, Bulmer D. The fine structure of the rat metrial gland in relation to the origin of the granulated cells. $J$ Anat 1977;126: 687-96.

13 Stewart I, Peel S. The structure and differentiation of granulated metrial gland cells of the pregnant mouse uterus. Cell Tissue Res 1977;184:517-27.

14 Gregory CD, Lee H, Scott IV, Golding PR. Phenotypic heterogeneity and recycling capacity of natural killer cells in normal human pregnancy. J Reprod Immunol 1987;11:135-45.

15 Bulmer JN, Johnson PM. Macrophage populations in the human placenta and amniochorion. Clin Exp Immunol 1984;57: 393-403.

16 Bulmer JN, Ritson A, Earl U, Hollings D. Immunocompetent cells in human decidua. In: Chaouat G. Reproductive immunology, materno-fetal relationship. Paris, Inserm, 1986;154:89-100.

17 Norton AJ, Ramsay AD, Smith SH, Beverley PCL, Isaacson PG. Monoclonal antibody (UCHL1) that recognises normal and neoplastic $\mathbf{T}$ cells in routinely fixed tissues. $J$ Clin Pathol 1986;39:399-405.

Requests for reprints to: Dr D Pace, Department of Pathology, University of Leeds, Leeds LS2 9JT, England. 